\title{
Precisamos falar de Marx: e isso pode começar pela comunicação organizacional
}

We need to talk about Marx: and this can start with organizational communication

Tenemos que hablar de Marx: y esto puede comenzar con la comunicación organizacional

Dôuglas Aparecido Ferreira

- Professor da Faculdade de Comunicação e Artes da Universidade Federal de Mato Grosso (UFMT).

- Doutorando em Comunicação Social na Universidade Federal de Minas Gerais (UFMG).

- Mestre em Interações Midiáticas pela Pontifícia Universidade Católica de Minas Gerais (PUC-Minas).

- Especialista em Gestão de Marcas e Identidade Corporativa pela PUC-Minas.

- Graduado em Comunicação Social: Gestão da Comunicação Integrada - habilitação em Publicidade e Propaganda - pela PUC-Minas.

- Membro do Grupo de Pesquisa em Imagem e Sociabilidade (GRIS) da UFMG

- Membro do Laboratório de Estudos e Observação em Publicidade, Comunicação e Sociedade (OPSlab) da UFMT.

- douglasferreira@ufmt.br 


\section{Resumo}

Este artigo é uma provocação teórica que parte da constatação de uma lacuna nos estudos da comunicação organizacional. Para isso, nos fundamentamos na aproximação de Marx com a perspectiva praxiológica de Quéré, entendendo que essa articulação pode trazer contribuições para as investigações das contradições do capitalismo. Como resultado, o artigo apresenta o esboço de um trajeto metodológico para compreender objetos da comunicação organizacional, de modo que se revelem as contradições do capitalismo, contribuindo para a transformação da realidade.

\section{PALAVRAS-CHAVE: CONTRADIÇÕES•CAPITALISMO • COMUNICAÇÃO ORGANIZACIONAL.}

\section{Abstract}

This paper is a theoretical provocation driven by a gap in the literature on Organizational Communication. It consists on the approximation of Marx with Quéré's praxiological perspective, understanding that such an articulation can contribute to investigations on the contradictions of capitalism. To this end, this study outlines a methodological path for understanding objects of Organizational Communication as to reveal the contradictions of capitalism and mediate reality transformation.

KEYWORDS: CONTRADICTIONS • CAPITALISM・ORGANIZATIONAL COMMUNICATION.

\section{Resumen}

Este artículo es una provocación teórica basada en una brecha en los estudios de comunicación organizacional. Para eso, se basa en la aproximación de Marx a la perspectiva praxiológica de Quéré, ya que esta articulación puede contribuir con las investigaciones de las contradicciones del capitalismo. Como resultado se presenta el esquema de un camino metodológico para entender los objetos de comunicación organizacional para que se revelen las contradicciones del capitalismo, lo que contribuye a la transformación de la realidad. 


\section{INTRODUÇÃO}

$\mathrm{E}$

ste artigo parte da concepção de que as recentes produções dos pesquisadores brasileiros na área da comunicação apresentam um baixo interesse na apreensão da realidade a partir da ótica marxiana' (Grohmann, 2016), mesmo reconhecendo que essa perspectiva traz um amplo debate crítico sobre as contradições do modo de produção capitalista e, consequentemente, contribui para a libertação dos trabalhadores da exploração de uma sociedade dividida em classes.

Neste sentido, amparados na ideia de que apenas fundamentalistas encaram a obra de Karl Marx como escritura sagrada (Eagleton, 2012), o que não é nosso caso, o objetivo deste artigo é apresentar uma articulação entre o pensamento marxiano e o modelo praxiológico da comunicação de Louis Quéré (2018). Nossa proposta se justifica por dois motivos: 1) as ideias de Marx, embora amplas, não são autossuficientes, sendo necessária uma suplementação teórica para dar conta de fenômenos específicos, como os da comunicação; e 2) as perspectivas de Marx e Quéré compartilham de fundamentos filosóficos semelhantes, o que possibilita essa empreitada de complementação.

Para tanto, 0 artigo se estrutura inicialmente com a apresentação de pesquisas que constatam a baixa utilização de Marx como referencial teórico dos estudos da comunicação e, mais especificamente, da comunicação organizacional. A seguir, visando entender os movimentos contraditórios que conformam a realidade, apresentaremos os passos utilizados por Marx em suas trajetórias analíticas. No intuito de atestar sua utilização nos objetos da comunicação organizacional, discorreremos sobre os eixos de pensamento comuns entre Marx e Quéré, o que nos permitirá aproximá-los e traçar zonas de complementariedade. Por fim, nas considerações finais, apresentaremos as possibilidades e os desafios que a articulação proposta pode trazer às pesquisas futuras.

\section{CONSTATAÇÕES INICIAIS}

Partimos do pressuposto de que Marx é um autor com pouco espaço nas produções acadêmicas em comunicação no Brasil. Uma das pesquisas que reforçam isso é a realizada por Grohmann (2016), envolvendo teses, dissertações e artigos, entre 2010 e 2014, abordando a temática classe social². A partir dos achados do investigador, pode-se inferir que, até quando se estuda uma das categorias centrais da obra de Marx - classes sociais -, o pensador alemão é pouco utilizado. No âmbito quantitativo, isso foi comprovado pela baixa incidência de referências ao autor, o que vai ao encontro da ideia de que "as escolhas sobre conceitos e autores, bem como todo o desenho de pesquisa, revelam lugares de fala e posicionamentos, inclusive com reapropriações conceituais a partir do olhar do pesquisador" (Grohmann, 2016, p. 23). Já qualitativamente, Grohmann (2016) identificou que, nas poucas vezes em que a literatura marxiana/marxista é acionada, ela traz problemas, como a banalização de conceitos e a invisibilização dos conflitos entre a classe trabalhadora ${ }^{3}$ e os donos do capital. "Não é raro encontrar pesquisas que acabam por transformar a desigualdade de classes em mera diferença" (Grohmann, 2016,

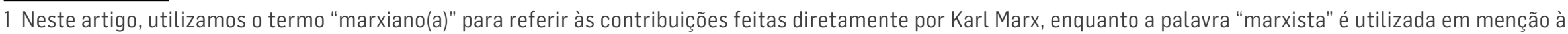
tradição de outros autores que dialogam com ele.

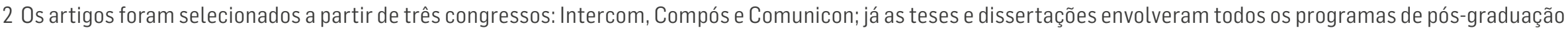

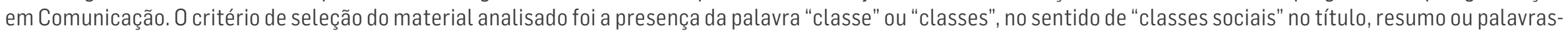
chave. 0 corpus foi constituído por 48 artigos, 32 dissertações e 10 teses.

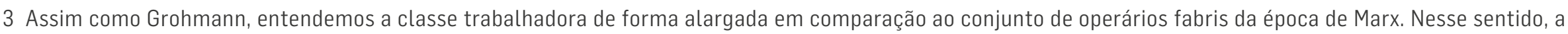

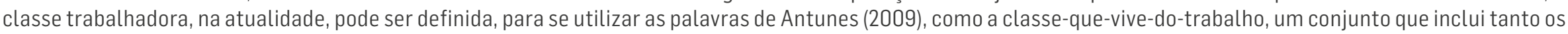

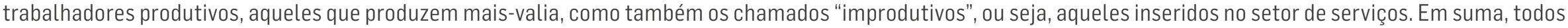

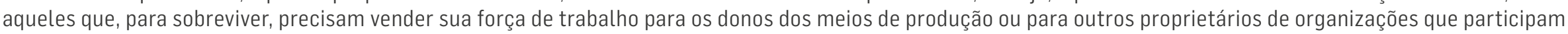

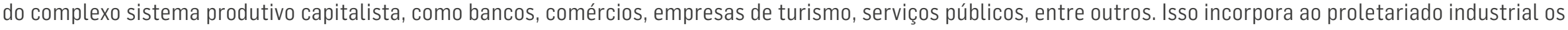

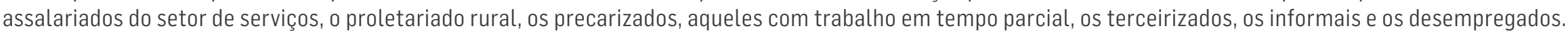


p.322). Isso aponta um excesso de culturalização nas análises que, segundo Grohmann (2016), romantiza as resistências cotidianas dos trabalhadores como se elas próprias fossem as únicas possibilidades viáveis de transformação, rejeitando qualquer forma de revolução mais estrutural do sistema produtivo.

Partindo da compreensão de que a relação com um autor não é somente utilitária, Grohmann (2016) destaca as implicações epistemológico-políticas do apagamento de Marx nas questões sobre a classe trabalhadora nos estudos da comunicação. Isso acontece, segundo ele, quando se considera esse assunto como superado, como se Marx não desse conta do "novo" capitalismo - conhecido também como informacional, cognitivo e imaterial. Dessa forma, muitas vezes o filósofo é substituído por autores chamados de pós-modernos, isto é, aqueles vinculados a uma linha de pensamento que enxerga o mundo como um conjunto de culturas desunificadas, que têm um certo grau de ceticismo em relação à objetividade e, portanto, rejeitam a existência de uma lógica própria da realidade social fundada na categoria trabalho (Eagleton, 2012). Ao terem essa concepção da realidade, os autores posicionados nessa corrente geralmente não se atentam às questões mais seminais do sistema produtivo e, consequentemente, suas produções causam uma falsa impressão de que a sociedade pode ser no máximo reformada, e não efetivamente transformada.

Além da investigação de Grohmann (2016), outras também chancelam nossa percepção do apagamento de Marx nos estudos da Comunicação. Entre elas, podemos mencionar a feita por Stumpf e Branco (2010) sobre as referências teóricas dos artigos entre 1985 e 2008 na Revista Brasileira de Ciências da Comunicação(Intercom). Seus resultados apontam que Marx não está entre os mais citados na área. Outra pesquisa, ainda mais abrangente em termos de quantidade de produção analisada, no entanto em menor período temporal, vai na mesma direção. Romancini (2006) analisou 503 dissertações e teses desenvolvidas em programas de pós-graduação brasileiros da área da comunicação. A partir de seus resultados, constatamos que foram feitas 26.740 citações utilizando-se autores estrangeiros, dessas, somente 47 eram de Marx. Mesmo reconhecendo que os dados apresentados não são recentes, acreditamos que o cenário pouco se modificou em relação ao uso da obra marxiana.

Na subárea da comunicação organizacional não é diferente. Marx não aparece em nenhuma das pesquisas que buscaram mapear os teóricos mais citados na produção acadêmica brasileira nos últimos anos (Bouzon; Oliveira, 2015; Curvello, 2018; Kunsch, 2011; Santos; Córdoba, 2019). Até em produções cuja temática central é a atividade laboral, o apagamento das contribuições de Marx se repete. Em busca feita no repositório da revista Organicom ${ }^{4}$, identificamos, nos últimos cinco anos, três artigos em que o tema central seja o trabalho ou o trabalhador ${ }^{5}$. Nenhum deles recorre a Marx em suas discussões.

De fato, reconhecemos que, nos estudos da comunicação organizacional, há uma pluralidade de temáticas, e nem todas objetivam abordar aspectos discutidos por Marx. Também sabemos que o autor não é um teórico da comunicação, o que certamente o faz não figurar entre os mais citados. Apesar disso, observamos, nas pesquisas mencionadas, que outros pensadores, como Zygmunt Bauman, Stuart Hall e Pierre Bourdieu, que também não têm a comunicação como tema central de suas ideias, ainda assim são mais resgatados do que Marx, mesmo em investigações nas quais o que se discute é o trabalho no capitalismo ${ }^{6}$.

\footnotetext{
4 Disponível em: https://bit.ly/3mBdkNd. Acesso em: 25 mar. 2021.

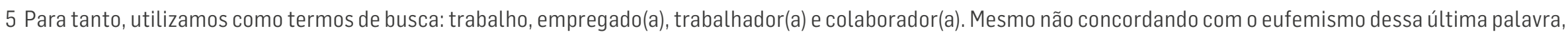

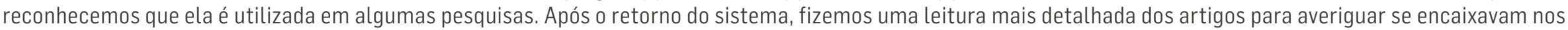

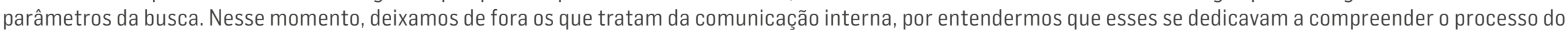

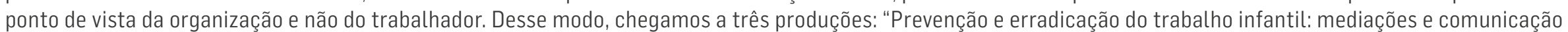

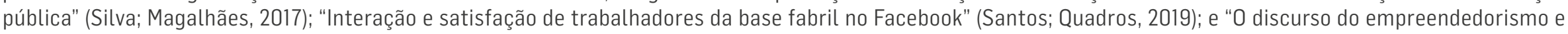
inovação nas relações de trabalho: um estudo de Vagas Arrombadas" (Silva; Lima, 2019).

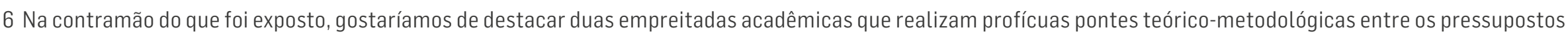

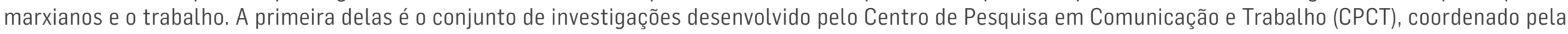

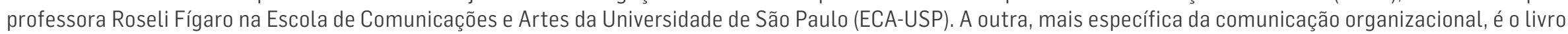

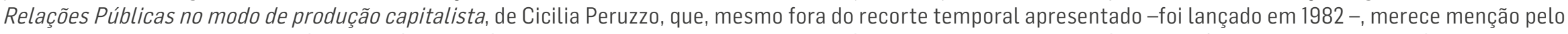
pioneirismo da abordagem do método histórico-dialético para entender a reprodução ideológica da burguesia no exercício do profissional de Relações Públicas.
} 
Isso não significa que os autores mais citados não possam dialogar com a perspectiva marxiana, inclusive atualizando-a. No entanto, deve-se considerar que, nas vezes em que essa atualização acontece, parte considerável do caráter revolucionário da teoria de Marx é substituída por visões integralistas entre os donos dos meios de produção e os trabalhadores. Essas perspectivas, características da literatura pós-moderna, pouco contribuem para a emancipação da classe trabalhadora das amarras ideológicas das classes dominantes (Tonet, 2013), e essa era uma das principais preocupações de Marx: que sua reflexão estivesse a serviço da transformação e da revolução, por isso seu interesse em analisar o movimento contraditório da realidade, para tirar do mundo a ideia de naturalidade da exploração. Aqui, entendemos por contradição aquilo que "acontece quando duas forças aparentemente opostas estão presentes ao mesmo tempo em determinada situação, entidade, processo ou evento" (Harvey, 2016, p.15), demonstrando que ela tem caráter ontológico, constituinte do mundo, e dialético, visto que essas forças opostas são interdependentes.

Não queremos reivindicar Marx como um pedágio obrigatório para toda pesquisa de comunicação organizacional, apenas chamamos a atenção para os riscos de se perder de vista suas principais contribuições, que ainda são importantes para 0 entendimento do impacto das contradições político-econômicas nos processos comunicacionais, já que "o esclarecimento dessas contradições deve revelar muita coisa sobre os problemas econômicos que tanto nos afligem" (Harvey, 2016, p.13). Portanto, ao desprezarmos os antagonismos organizadores da sociedade capitalista, podemos cair na normalização de seus dualismos estruturantes, resultando em pesquisas que, nem sempre de modo intencional, reforçam os interesses das classes dominantes e reafirmam o capitalismo como um sistema coerente e insuperável. Ao fazermos isso, estamos produzindo um tipo de pensamento combatido por Marx (1999), uma vez que não contribui para a transformação efetiva da realidade dos trabalhadores. Na mesma esteira, Eagleton afirma que "afinal, se não resistirmos ao que é aparentemente inevitável, jamais saberemos quão inevitável era o inevitável" (2012, p.14).

O panorama descrito nos leva a pensar sobre a importância de os estudos da comunicação não perderem de vista as contribuições de Marx, e como isso pode ser encabeçado pela subárea da comunicação organizacional, visto que é nas organizações que se estabelece uma das principais contradições do mundo capitalista: a prática social do trabalho executada a serviço do interesse particular de uma pessoa ou de um grupo que controla os meios de produção. Portanto, olhar para as organizações como uma multiplicidade de sínteses dialéticas contribui significativamente para se pensar nos processos de comunicação em seu contexto como um complexo também contraditório de emancipação e prisão, expressão e expropriação, riqueza e pobreza (Grohmann, 2016).

Não defendemos, porém, que a perspectiva marxiana, elaborada em meados do séculoXIX, possa ser meramente transposta para os dias de hoje de forma acrítica e atemporal. 0 próprio pensador tinha consciência disso, reconhecendo que "a humanidade não se propõe nunca senão os problemas que ela pode resolver, pois, aprofundando a análise, ver-se-á sempre que o próprio problema só se apresenta quando as condições materiais para resolvê-lo existem ou estão em vias de existir" (Marx, 2008, p.48). Isso significa que a sociedade está em um constante processo de transformação e que cada tempo histórico tem suas particularidades e desafios. No entanto, também parece ingênuo pensar que as linhas mais gerais do capitalismo estejam completamente superadas e que se vive, hoje, em uma sociedade em que não há a exploração de uma classe sobre a outra ou a interferência do modo produtivo nas questões políticas, sociais, culturais e artísticas.

\section{O TRAJETO METODOLÓGICO DE MARX E SUA APLICAÇÃO NA COMUNICAÇÃO ORGANIZACIONAL A PARTIR DE UMA PERSPECTIVA PRAXIOLÓGICA}

Marx não elaborou um esquema metodológico, no sentido estrito da palavra, para apreender a dinâmica das determinações contraditórias constitutivas da realidade, no entanto, no conjunto de sua obra, é possível identificar a trajetória que utilizava 
para compreender o resultado da ação dos humanos. A primeira etapa de seu curso investigativo parte do que ele chama de "concreto representado" (Marx, 2008), isto é, da realidade carregada de atribuições de significados derivados da experiência imediata do sujeito, portanto, caótica e indeterminada. A partir disso, sem a necessidade de qualquer categoria apriorística, no intuito de evitar falseamentos idealistas, busca-se reconstruir o objeto concreto na consciência, deslindando suas categorias constitutivas, desincrustando de sua complexidade as partes mais simples constituintes.

Marx (2008) chama esse momento de "formulação do concreto abstrato": a reprodução, na consciência, do movimento dos objetos, das contradições e das relações que configuram sua existência na história, elementos não evidentes no concreto representado. Esses estão presentes no próprio objeto, mas se encontram encobertos porque o que se vê de imediato é apenas uma síntese dessas imbricações. Portanto, se o concreto representado é a soma das relações de muitas determinações históricas, ao apreendê-lo como um concreto abstrato, a função da pesquisa passa a ser reproduzir, agora no nível do pensamento, os processos constitutivos do que está sendo analisado. Assim, desvelando esse novelo, é possível compreender a complexidade histórica do que incialmente se apresentava apenas como dado.

Nessas condições de investigação, o objeto é o polo regente do conhecimento, não o pesquisador. Isso não significa que a subjetividade seja menos importante, mas que os objetos existem para além dela e, portanto, o desafio dos sujeitos é compreendê-los. Em suma, o objetivo do modo investigativo de Marx não é encontrar os conceitos das coisas - perspectiva gnosiológica-, mas buscar seus processos constitutivos - perspectiva ontológica. Assim, mesmo quando o investigador não parte da dimensão ontológica, não significa que ela não exista: ela está lá, de forma implícita em sua análise ou negada pela abordagem teórico-metodológica adotada (Tonet, 2013).

Após partir do concreto representado para o concreto abstrato, Marx (2008) propõe uma viagem de retorno, ou seja, a observação do objeto não mais de forma imediata, mas mediado pelas reflexões de suas contradições constitutivas. Assim, o concreto deixa de ser uma representação caótica e passa a ser um rico composto de muitas dinâmicas. É nesse caminho de volta ao concreto, observando-o agora servido da apreensão dos processos que o compõem, que distingue a proposta de Marx dos idealistas - que partem do abstrato para o concreto -, e dos empiristas - que partem do concreto para 0 abstrato sem fazer o caminho de retorno. Em suma, em Marx, o concreto é o ponto de partida e de chegada, e entre esses dois está a mediação da abstração do investigador.

0 caminho utilizado por Marx (2008) se mostra como um potente primeiro contato analítico com o objeto. Isto é, antes de se responder às questões de ordem gnosiológicas, como, por exemplo, entender as relações de poder presentes nos discursos organizacionais, é importante delimitar a dimensão ontológica daquilo que se pesquisa. Nesse caso, refletir sobre as categorias históricas constitutivas embutidas nos discursos organizacionais que os faz se apresentarem na realidade da forma que são, e não de outra. Prezar pelo estudo das determinações que constituem o objeto é um esforço para que o conhecimento científico não caia no excesso de subjetividade, tornando quase impossível que os achados de um campo do conhecimento possam ser criticados ou revisados devido à expressiva quantidade de abstrações.

Todavia, apesar de enxergarmos potencialidades de aplicação do método descrito, esbarramos em uma afirmação de Marx que, aparentemente, demonstra que sua perspectiva comunicacional não abre espaço para que seu estilo investigativo seja aplicado a objetos da comunicação. Ao afirmar que "não partimos do que os homens dizem, imaginam e representam, tampouco do que eles são nas palavras [...], mas partimos dos homens em sua atividade real" (Marx; Engels, 2001, p.18), 0 autor nos leva a crer que entendia os processos comunicacionais como atividades representacionais, não como atividade 
concreta constituinte da realidade ${ }^{7}$. É neste ponto que a trajetória de análise marxiana pode ser atualizada por Quéré e, consequentemente, passa a ter o potencial de utilização na comunicação organizacional.

A aproximação entre o pensamento marxiano e o modelo praxiológico da comunicação (Quéré, 2018) é possível quando se considera que a chave de leitura utilizada por ambos para a compreensão da realidade social está fundamentada na observação da concretude da ação coletiva humana na arena pública. Essa característica em comum está amparada na rejeição de categorias analíticas apriorísticas e abordagens idealistas, isto é, perspectivas que separam o pensar do agir.

Os eixos basilares das principais influências filosóficas - o materialismo histórico-dialético para Marx e o pragmatismo para Quéré - também nos encorajam a fazer a aproximação proposta. Embora estejamos tratando de tradições diferentes, é possível, por exemplo, identificar traços do pragmatismo na obra de Marx, mesmo cientes de que o filósofo não reconheça isso em seus textos.

A respeito disso, Souza (2012) define Marx como um "bom pragmatista". Isso se deve porque o filósofo introduziu o agir nas dimensões do conhecer e do ser, "construindo uma relação prática entre real e ideal" (p.118), aspecto comum na tradição pragmatista. Já Pogrebinschi (2005) destaca que a filosofia pragmatista é, sem dúvida, tão prática quanto a marxiana. A constatação da autora pode ser identificada na passagem em que Marx afirma que "a vida social é essencialmente prática. Todos os mistérios que desviam a teoria para o misticismo encontram sua solução racional na prática humana e na compreensão desta prática" (Marx, 1999, p.7). Além da centralidade da prática, pode-se ainda perceber, nas ideias de Marx, a presença de três aspectos que compõem as bases do pragmatismo: 0 antifundamentalismo - rejeição a princípios imutáveis e apriorísticos -, o contextualismo - ênfase na atuação do contexto no desenvolvimento do pensamento -, e o consequencialismo - a aceitação de que as ações humanas interferem na história (Pogrebinschi, 2005). No mesmo sentido, Joas (1999) reforça que Marx se torna incompreensível quando não se entende sua teoria fundamentada na ação, e esse é outro ponto que o liga ao pragmatismo, ou seja, olhar para os sujeitos atuando em atividades conjuntas em uma determinada situação.

Embora seja compreensível que Marx (2015) esteja mais interessado no entendimento da exploração do trabalho no bojo de uma sociedade organizada pela divisão de classes, e que Quéré (2018) se volte para a análise dos fenômenos sociais a partir de uma perspectiva comunicacional, inferimos que outro ponto de afinidade teórica está no fato de ambos partirem de uma concepção ampliada dos conceitos centrais de suas reflexões. Quéré (2018) olha para a comunicação não como um fenômeno meramente representacional ou com intencionalidades prévias, mas como efetivamente uma ação coletiva, uma atividade com capacidade constitutiva, tanto da subjetividade dos sujeitos quanto da objetividade do mundo.

Em conceituação também abrangente, Marx (2015) define o trabalho como toda atividade social de interferência objetiva que garanta a sobrevivência humana, que tem por consequência a transformação do meio e do próprio sujeito que o executa, visto que, a cada novo objeto construído, novas possibilidades lhe são apresentadas. Em outras palavras, para Marx (2015), o trabalho é uma característica ontológica do ser social, uma vez que é a categoria que permite ao ser humano superar as determinações da natureza e construir sua própria história em sociedade. Sua abordagem, portanto, rejeita perspectivas que enxergam o trabalho apenas em sua forma de emprego assalariado, como venda e compra da força de trabalho no mundo capitalista.

Ao alargarem os conceitos de trabalho e comunicação, Marx e Quéré, respectivamente, passam a reconhecer os sujeitos não mais como espectadores contemplativos de suas histórias ou como reles atores que representam linguisticamente a

7 Isso não significa dizer que o filósofo dava menos importância aos aspectos comunicacionais na vida social, inclusive, em um outro trecho, ele destaca: "a linguagem é tão antiga quanto a consciência - a linguagem é a consciência real, prática, que existe também para os outros homens, que existe, portanto, também primeiro para mim mesmo e, exatamente como a consciência, a linguagem só aparece com a carência, com a necessidade dos intercâmbios com os outros homens" (Marx; Engels, 2001, p.24-25). Assim, entendemos que Marx reconhecia a comunicação como uma categoria essencial, mas não a reconhecia como uma ação concreta. 
realidade. A ampliação da concepção de trabalho e comunicação ajuda os pensadores a verem essas categorias como formas genuínas de ação e como processos constituidores da objetividade e da subjetividade, levando-os a entender que não há outro real para além daquele construído pela atividade social dos humanos. Assim, trabalho e comunicação são entendidos como ações coletivas que produzem constantemente o novo no mundo e, portanto, têm potencial de mudar a realidade e os sujeitos nelas envolvidos.

As proximidades teóricas apresentadas nos levam também a pensar os pontos de complementariedade entre os autores. Neste sentido, Quéré (2018) nos ajuda a colocar a comunicação no conjunto das atividades de criação e transformação da realidade - característica que o pensamento marxiano identificava no trabalho -, mas pouco disse sobre outros processos paralelos. De modo recursivo, Marx, ao entender as práticas da vida social como sínteses das contradições do sistema produtivo, traz a possibilidade de compreendermos a comunicação como uma atividade que se realiza sob condições de disputas de forças antagônicas, conformadoras do agir dos seres humanos em cada tempo histórico. Essa contribuição se baseia em uma das mais célebres frases do pensador: "os homens fazem sua própria história; contudo, não a fazem de livre e espontânea vontade, pois não são eles quem escolhem as circunstâncias sob as quais ela é feita, mas estas lhes foram transmitidas assim como se encontram" (Marx, 2011, p.25).

A última citação é um convite de Marx para a apreensão dos movimentos conflituosos e das dinâmicas contraditórias do sistema produtivo que interferem no cotidiano, encarando a práxis como um composto dialético entre a subjetividade dos sujeitos e a objetividade do sistema produtivo no qual estão inseridos. "O modo de produção da vida material condiciona 0 processo de vida social, política e intelectual. Não é a consciência dos homens que determina o seu ser; ao contrário, é o seu ser social que determina sua consciência" (Marx, 2008, p.47). Cabe destacar que as determinações, para Marx, não significam a total falta de inventividade dos humanos; na verdade, o pensador está chamando atenção para o fato de que o presente é também constituído dos movimentos históricos anteriores a ele. Esses últimos, segundo Marx (2015), são agenciados pelos próprios humanos, o que nos leva a concluir que os seres humanos agem - se comunicam - sob condições pré-existentes criadas pelos próprios seres humanos.

É nesse sentido que os processos sociais do presente só podem existir porque têm em si traços de determinações de acontecimentos anteriores. Essas determinações se manifestam na vida social na forma de fenômenos singulares, em objetos únicos que trazem em si a síntese contraditória das forças determinantes constituintes da realidade e a singularidade da experiência fenomênica. Essa é a relação dialética entre passado e presente, entre a continuidade e o ineditismo: só é possível existir o singular no mundo porque ele é uma expressão fenomênica composta por múltiplas determinações nele contidas. 0 que foi dito é resumido por Lukács (2018) ao dizer que: "a singularidade é, precisamente, tal como a generalidade, uma das categorias fundamentais de todo ser: não há existente que não exista ao mesmo tempo como exemplar de seu gênero (geral) e como objetividade única (singular)" (p.44).

É por esse motivo que as determinações para Marx não são condições abstratas inevitáveis, visto que são resultantes dos agenciamentos concretos dos próprios seres humanos e de suas escolhas organizativas da sociedade; assim como também não são estanques, uma vez que são processualidades suscetíveis a modificações todas as vezes que se manifestam na singularidade de um fenômeno. Assim, a relação entre singularidade e determinação é dialógica: os momentos singularizantes são a mediação indispensável para a existência das determinações históricas, levando essas últimas a uma constante transformação, ao passo que cada fenômeno singular só é possível devido aos traços de continuidade de seu tempo neles inscritos. Portanto, Marx não nega a inventividade humana, ele apenas destaca que o novo é dialeticamente constituído do velho nele incutido. "Por isso, cada momento do processo é único, irrepetível - o que quer dizer, é novo, inédito - e, concomitantemente, é portador de todas as determinações passadas que condicionaram sua gênese" (Lessa, 2001, p.93). 
Tomar essa reflexão nos objetos de estudo da comunicação organizacional é pensar que, sem as determinações do modo de produção, os processos comunicacionais seriam o mais absoluto caos de ineditismos, pois não possuiriam qualquer conexão de continuidade com seu tempo. Assim como, sem a singularidade de cada fenômeno comunicacional, os processos de determinações desapareciam, visto que não haveria a possiblidade de se manifestarem no real.

Também cabe dizer que, ao falar de determinações do modo de produção, a contribuição de Marx aparenta se limitar a objetos investigativos de característica macrossocial. Embora, de fato, essa seja a principal preocupação do autor, o perfil dialético de seu pensamento nos leva a discordar dessa ideia. Isso porque é possível utilizar a reflexão marxiana na compreensão da constituição também dos objetos da vida cotidiana, já que no micro estão contidas as determinações materiais de um tempo. A realidade é a síntese do micro e do macro, do fenomênico e do histórico, do singular e do contínuo, e nisso está o desafio e a riqueza de entender essas contradições, essas forças opostas que constituem a realidade, afinal, elas são, ao mesmo tempo, a afirmação e a negação de alguma coisa. Isso, levado ao estudo da comunicação organizacional, é entender que, como é dito por Grohmann (2016), nem tudo é só dominação/estrutura e nem só resistência/ação.

As contradições do capitalismo não podem ser desprezadas no processo de compreensão dos objetos que compõem a vida social, sejam de natureza micro ou macro. A respeito disso, Grohmann (2014) explica que

É preciso, nos estudos de comunicação, compreender dialeticamente a realidade, a partir da dinâmica e das contradições da vida social, na relação metodológica e teórica entre o "micro" e o "macro", considerando os sujeitos como seres sociais, relacionando seus discursos e práticas à sociedade onde se vive. (p.227)

A partir do que já foi apresentado, concordamos com Quéré (2018), para quem a comunicação constitui objetivamente 0 mundo, cria de fato uma realidade coletiva entre os seres humanos. Porém, visto que há determinações presentes no sistema produtivo que organizam a vida social de cada tempo histórico, pensar o poder constitutivo da comunicação como autônomo é pensá-lo como imaculado da dialética que institui o mundo. Assim, achamos importante essa ponte entre Quéré e Marx, ou seja, concordamos que os processos de comunicação são ações que constituem e transformam a realidade, no entanto, quando essa afirmação é tomada sem a observância das determinações históricas e materiais de uma sociedade, pode-se levar a falsas impressões de total liberdade e inventividade das atividades dos sujeitos. Isso leva ao que Marx (2015) chamou de "fetichismo": a percepção de que o modo como as coisas se apresentam é sua totalidade, de modo que sua constituição, os processos ontológicos contraditórios nelas embutidos, são desconsiderados. Assim, o fetichismo na comunicação aconteceria quando se esquece que até mesmo o que os processos comunicacionais instituem como novo é, dialeticamente, formado por traços do passado, que, contraditoriamente, aparentam estar superados, quando, na verdade, têm relação de interdependência com o que é criado.

Portanto, retomando a trajetória analítica de Marx, ir do concreto representado ao concreto pensado e, depois, retornar ao concreto agora compreendido em suas contradições constitutivas pode ser aplicado a vários objetos pesquisados pela comunicação organizacional - como campanhas, ações institucionais, processos internos de comunicação, documentos, materiais audiovisuais, discursos oficiais e não oficiais, crises de imagem e estudos de reputação e marcas -, desde que esses sejam vistos como ações objetivas dos seres humanos com potencial de transformação da realidade. E é exatamente isso que Quéré (2018) propõe ao pensar a comunicação, por isso, também é possível compreendê-la a partir de suas determinações contraditórias constitutivas. Nesse sentido, o objeto comunicacional analisado deixa de ser um mero recorte do presente e passa a ser a síntese de uma ação que constrói o mundo (Quéré, 2018), isto é, aponta para o futuro, ao passo que é determinada pelos processos que a antecedem (Marx, 2008). Em suma, a complementariedade entre os autores poderia ser resumida como: os sujeitos constroem a realidade, inclusive as organizações, a partir de seus processos comunicacionais, não de acordo 
com sua própria vontade, mas com as determinações contraditórias históricas e materiais de seu tempo, essas também de responsabilidade dos sujeitos.

Acreditamos que outro ganho da aplicação conjugada do pensamento de Marx e Quéré é a contribuição para a consolidação da comunicação como um campo legítimo do conhecimento. Isso se dá pelo fato de que, colocando os objetos investigados como centrais nas análises, destacando que as demandas metodológicas partem deles, torna-se desnecessário utilizar ferramentas analíticas com categorias apriorísticas, visto que as atividades comunicacionais analisadas dizem por elas próprias a realidade em que acontecem, pois são a síntese das forças constitutivas do mundo, basta ao pesquisador reproduzilas conscientemente e compreendê-las para que sejam transformadas. 0 que não reduz a importância de o pesquisador ter à disposição um repertório consolidado de leituras que o ajudarão nessa etapa de decomposição da complexidade da realidade representada.

Por fim, não queremos afirmar que, por não utilizarem a perspectiva histórico-dialética marxiana, as pesquisas em comunicação organizacional deixam de observar as determinações que constituem a sociedade. Obviamente, é possível chegar a essas conclusões por outras vias. 0 que pontuamos são os ganhos que a consolidação de uma ciência que se posiciona do lado dos oprimidos pode trazer para os estudos dessa subárea. Isso pode ser alcançado pelas principais ideias de Marx, principalmente quando resgatadas suas noções ontológicas do ser social, sua observação minuciosa das contradições que constituem realidade, sua visão da objetividade como polo regente do conhecimento, sua preocupação em superar uma sociedade de classes e em seu modo de fazer pesquisa, voltado para a vida em sua concretude, no movimento da sociedade a partir das ações constantes dos seres humanos e no fim da exploração dos trabalhadores.

\section{CONSIDERAÇÕES FINAIS}

Partimos do pressuposto de que a comunicação não é um mero processo representacional, ela é uma ação coletiva concreta que (re)constrói objetiva e subjetivamente o mundo (Quéré, 2018). Isso colocado, nos apoiamos em Marx (2015) para demonstrar que essa ação ocorre no bojo das contradições de seu tempo histórico, derivadas do sistema produtivo organizador da sociedade e que, portanto, a comunicação é, de fato, uma prática. Contudo, uma prática tão contraditória como qualquer outra atividade social e que, por mais que apresente o potencial de criar, traz em si, dialeticamente, o passado, de modo que somente uma grande cisão - como uma revolução - teria o potencial de interromper seus traços de reprodução da continuidade.

A intenção de nosso convite para trazer - ou trazer de volta - a reflexão marxiana para os estudos da comunicação organizacional, atualizada com a perspectiva de Quéré, está no fato de acreditarmos que essa subárea poderá tanto contribuir em pontos não desenvolvidos por esses autores - como as especificidades dos processos comunicacionais no contexto das organizações quanto se apropriar dessa combinação para a compreensão da ontologia contraditória de seus objetos de estudo, visto que as organizações se apresentam como sínteses mais aparentes das determinações do capitalismo. Assim, fazer essa incursão ontológica, desincrustando os processos constitutivos dos objetos e, em seguida, voltar a eles com suas partes identificadas para, aí sim, responder às questões específicas do campo, é um caminho para se evitar conclusões que favorecem a consolidação da realidade como dada, ponto combatido pela filosofia revolucionária de Marx. Isso não significa desconsiderar todo 0 acúmulo epistemológico já construído pela subárea. Ele continua importante e deve ser adotado sempre que necessário. 0 detalhe para o qual chamamos a atenção é que, muitas vezes, se parte da concepção de um mundo já consolidado, o que nos parece pouco efetivo para fazer emergir as contradições do capitalismo e, consequentemente, contribuir com a libertação da classe trabalhadora. 
Por fim, tentamos atualizar os conceitos de Marx e desmitificar algumas críticas a seu pensamento, pontos que podem ter sido o motivo de sua invisibilidade nas pesquisas da comunicação. Fizemos isso demonstrando que suas contribuições não são só econômicas, que sua abordagem não é determinista, e que seu pensamento ainda é potente para entender um sistema produtivo que não foi superado, embora a cada dia se apresente mais sofisticado. Assim, esperamos que este artigo seja um incentivo tanto para quem gostaria de começar a dialogar com a literatura marxiana quanto para quem se sente provocado a questionar sua perspectiva e aplicabilidade nos estudos da comunicação organizacional.

\section{REFERÊNCIAS}

ANTUNES, Ricardo. Os sentidos do trabalho: ensaio sobre a afirmação e a negação do trabalho.11.ed. São Paulo: Boitempo, 2009.

BOUZON, Arlette; OLIVEIRA, Ivone de Lourdes de. As revistas científicas de comunicação organizacional e suas marcas epistemológicas: um estudo comparativo entre França e Brasil. Intercom: Revista Brasileira de Ciências da Comunicação, São Paulo, v.38, n.1, p.129-149, 2015.

CÓRDOBA, Sandra Orjuela. Entendiendo la comunicación en la organización a través de 10 revistas latinoamericanas. Organicom, São Paulo, v.16, n.30, p.152-163, 2019.

EAGLETON, Terry. Marx estava certo. Rio de Janeiro: Nova Fronteira, 2012.

GROHMANN, Rafael. Marx de volta? Na comunicação? Revista Mídia e Cotidiano, Niterói, v.4, n.4, p.213-231, 2014.

GROHMANN, Rafael. As classes sociais na comunicação: sentidos teóricos do conceito. 2016. Tese (Doutorado em Ciências da Comunicação) - Escola de Comunicações e Artes, Universidade de São Paulo, São Paulo, 2016.

HARVEY, David. 17 contradições e o fim do capitalismo. São Paulo: Boitempo, 2016.

JOAS, Hans. Interacionismo simbólico. In: GIDDENS, Anthony, TURNER, Jonathan (org.). Teoria social hoje. São Paulo: Ed. Unesp, 1999. p.127-174.

KUNSCH, Margarida Krohling. Comunicação organizacional e Relações Públicas: perspectivas dos estudos latino-americanos. Revista Internacional de Relaciones Públicas, Málaga, v.1, n.1, p.69-96, 2011.

LESSA, Sérgio. Lukács e a ontologia: uma introdução. Outubro, São Paulo, n.5, p.83-100, 2001.

LUKÁCS, G. Para uma ontologia do ser social. Maceió: Coletivo Veredas, 2018.

MARX, Karl. Teses sobre Feuerbach. [S.L.]: Ed. Ridendo Castigat Mores, 1999.

MARX, Karl. Contribuição à crítica da economia política. 2.ed. São Paulo: Expressão Popular, 2008.

MARX, Karl. 018 de brumário de Luís Bonaparte. São Paulo: Boitempo, 2011.

MARX, Karl. O Capital: crítica da economia política. Livro 1: 0 processo de produção do capital. São Paulo: Boitempo, 2015. 
MARX, Karl; ENGELS, Friedrich. A ideologia alemã. São Paulo: Martins Fontes, 2001.

POGREBINSCHI, Thamy. Pragmatismo: teoria social e política. Rio de Janeiro: Relume Dumará, 2005.

QUÉRÉ, Louis. De um modelo epistemológico da comunicação a um modelo praxiológico. In: FRANÇA, Vera Veiga; SIMÕES, Paula (org.). O modelo praxiológico e os desafios da pesquisa em comunicação. Porto Alegre: Sulina, 2018. p.15-50.

ROMANCINI, Richard. O campo científico da comunicação no Brasil: institucionalização e capital científico. 2006. Tese (Doutorado em Ciências da Comunicação) - Escola de Comunicações e Artes, Universidade de São Paulo, São Paulo, 2006.

SANTOS, Gustavo Azevedo da Silva; CURVELLO, João José Azevedo. Teorias da comunicação organizacional: produção científica da Abrapcorp entre 2011 e 2012. In: CONGRESSO ABRAPCORP, 12., 2018, Goiânia. Anais [...]. Goiânia: Abrapcorp, 2018. p.169-175.

SANTOS, Maria Lúcia Salgueiro dos; QUADROS, Claudia Irene de. Interação e satisfação de trabalhadores da base fabril no Facebook. Organicom, São Paulo, v.16, n.31, p.69-82, 2019.

SILVA, Daniel Reis; LIMA, Fábia Pereira. 0 discurso do empreendedorismo e inovação nas relações de trabalho. Organicom, São Paulo, v.16, n.31, p.172-183, 2019.

SILVA, Luíza Mônica Assis; MAGALHÃES, Daniella Rocha. Prevenção e erradicação do trabalho infantil: mediações e comunicação pública. Organicom, São Paulo, v.14, n.26, p.204-213, 2017.

SOUZA, José Crisóstomo de. Teses ad Marx: para uma crítica ao (não-)pragmatismo de Marx. Cognitio, São Paulo, v.13, n.1, p.115-144, 2012.

STUMPF, Ida Regina Chittó; BRANCO, Zuleika de Souza. Análise de citações dos artigos da Intercom - Revista Brasileira de Ciências da Comunicação (1985-2008). Informação \& Informação, Londrina, v.15, n.1esp., p.93-109, 2010.

TONET, Ivo. Método científico: uma abordagem ontológica. São Paulo: Instituto Lukács, 2013.

Artigo recebido em 14.05.2021 e aprovado em 09.08.2021. 